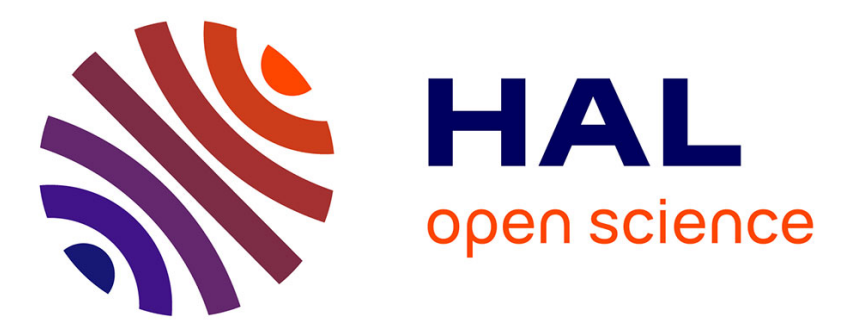

\title{
Direct keyhole laser welding of aluminum alloy AA5754 to titanium alloy Ti6Al4V
}

I Tomashchuk, P Sallamand, E Cicala, Patrice Peyre, D Grevey

\section{To cite this version:}

I Tomashchuk, P Sallamand, E Cicala, Patrice Peyre, D Grevey. Direct keyhole laser welding of aluminum alloy AA5754 to titanium alloy Ti6Al4V. Journal of Materials Processing Technology, 2014, 217, pp.96-104. 10.1016/j.jmatprotec.2014.10.025 . hal-01090999

\section{HAL Id: hal-01090999 \\ https://hal.science/hal-01090999}

Submitted on 4 Dec 2014

HAL is a multi-disciplinary open access archive for the deposit and dissemination of scientific research documents, whether they are published or not. The documents may come from teaching and research institutions in France or abroad, or from public or private research centers.
L'archive ouverte pluridisciplinaire HAL, est destinée au dépôt et à la diffusion de documents scientifiques de niveau recherche, publiés ou non, émanant des établissements d'enseignement et de recherche français ou étrangers, des laboratoires publics ou privés. 


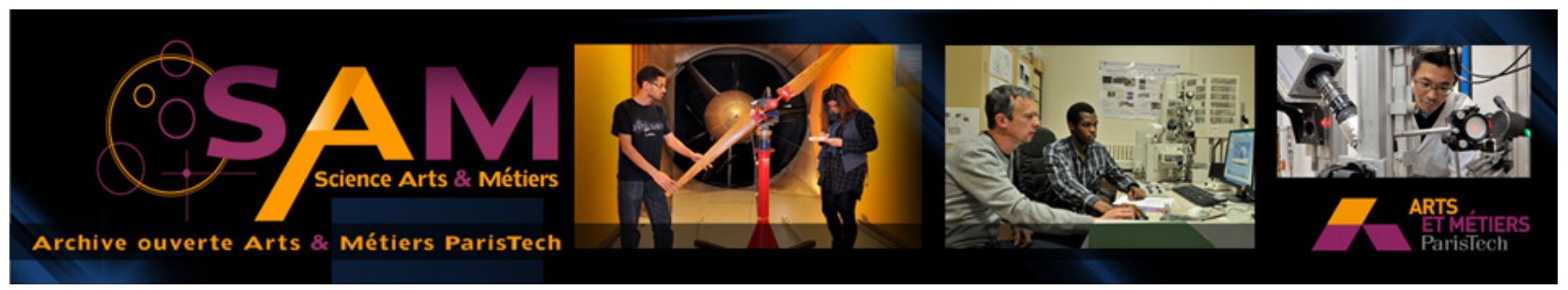

Science Arts \& Métiers (SAM)

is an open access repository that collects the work of Arts et Métiers ParisTech researchers and makes it freely available over the web where possible.

This is an author-deposited version published in: http://sam.ensam.eu

Handle ID: .http://hdl.handle.net/10985/9060

\section{To cite this version :}

I TOMASHCHUK, P SALLAMAND, E CICALA, Patrice PEYRE, D GREVEY - Direct keyhole laser welding of aluminum alloy AA5754 to titanium alloy Ti6AI4V - Journal of Materials Processing Technology - Vol. 217, p.96-104 - 2014 


\title{
Direct keyhole laser welding of aluminum alloy AA5754 to titanium alloy Ti6Al4V
}

\author{
I. Tomashchuk ${ }^{\mathrm{a}, *}$, P. Sallamand ${ }^{\mathrm{a}}$, E. Cicala ${ }^{\mathrm{a}}$, P. Peyre ${ }^{\mathrm{b}}$, D. Grevey ${ }^{\mathrm{a}}$ \\ a Laboratoire Interdisciplinaire Carnot de Bourgogne, UMR 6303 CNRS/Université de Bourgogne, 12, rue de la Fonderie, 71200 Le Creusot, France \\ b PIMM Laboratory, UMR 8006 CNRS-Arts et Métiers ParisTech, 151 Bd de l'Hôpital, 75013 Paris, France
}

Keywords:

Laser welding

Dissimilar metal joint

Titanium alloys

Aluminum alloys

\begin{abstract}
A B S T R A C T
The tensile strength of direct AA5754/Ti6Al4V joints performed by high speed Yb:YAG laser welding is found to be determined by morphology and phase content of dissimilar interface formed between contacting Al-rich and Ti-rich melted zones. Three types of contact interfaces were observed: (1) thin $(<20 \mu \mathrm{m}$ thick) interface composed mostly by TiAl and formed under $0.2 \mathrm{~mm}$ beam shift to $\mathrm{Al}$ side and linear energy of welding $\geq 37.5 \mathrm{~kJ} / \mathrm{m}$; (2) cracked interface (190-300 $\mu \mathrm{m}$ thick) composed by $\mathrm{Al}_{3} \mathrm{Ti}$ and other Al-Ti intermetallics and formed under beam shift at $0.2 \mathrm{~mm}$ to Ti side and linear energy $\geq 37.5 \mathrm{~kJ} / \mathrm{m}$; (3) malaxated interface composed of layers and isles of $\mathrm{Ti}_{3} \mathrm{Al}$ and $\mathrm{TiAl}$ forming in other tested conditions and favored by welding speed $>10 \mathrm{~m} / \mathrm{min}$.

Maximal linear tensile force ( $220 \mathrm{~N} / \mathrm{mm}$ for $2 \mathrm{~mm}$ thick weld) can be attained when thin contact interface is formed. In this case, the fracture starts in intermetallics-rich zone but propagates mainly in Al-rich melted zone, when in other cases it occurs in brittle intermetallic layers.
\end{abstract}

\section{Introduction}

The combination of aluminum and titanium-based parts in lightened hybrid structures becomes relevant for application in transport and aircraft industries. However, joining of this couple and their alloys remains a difficult technological task because of important missmatch in physical properties, limited mutual solubility and formation of intermetallic phases in aluminum-titanium (Al-Ti) system reported by Raghavan (2005).

The successful joining of aluminum to titanium demands the reduction of thickness of potentially brittle intermetallic zones. Jiangwei et al. (2002) report the possibility of diffusion bonding of these alloys, Fuji et al. (1997) succeed in friction welding, Okamura and Aota (2004) report quality joining by friction stir welding, Ege and Inal (2000) performed explosive welding. Takemoto and Okamoto (1988) report the possibility of joining by brazing. The common thing for all these tested methods is that convective mixing and diffusion phenomena are suppressed or very attenuated, so bulk brittle intermetallics do not form. Another remedy against brittle phases is the modification of the chemistry of melted zone: Chang et al. (2012) report the positive effect of addition of

\footnotetext{
* Corresponding author. Tel.: +33 3857311 23; fax: +33 385731120 .

E-mail addresses: iryna.tomashchuk@u-bourgogne.fr, iryna84@hotmail.fr (I. Tomashchuk).
}

rare-earth elements for aluminum/titanium joining by vacuum brazing, Sambasiva Rao et al. (2011) used Si-containing filler wire for TIG welding of aluminum to titanium alloy.

Laser welding opens an attractive perspective for joining strongly dissimilar materials. Sun and Ion (1995) reported successful laser welding of many dissimilar couples of metals and alloys. The main advantage of laser welding consists in providing very local energy supply that allows obtaining thin and high precision welds and reducing thermal distortion. Small interaction zone and high welding speed promote high thermal gradients, which are useful for local phase content optimization. So, the importance of mixing and diffusion phenomena can be reduced. Moreover, the mismatch in thermophysical properties of chosen dissimilar couple can be adjusted by shifting the laser beam to one of the substrates.

Recently many new metal combinations were successfully joined by laser: Zhao et al. (2013) report titanium/lead joining, Tomashchuk et al. (2011) carried out titanium to steel welding via copper interlayer, Mathieu et al. (2006) and Sierra et al. (2007) carried out aluminum to steel welding.

Many studies on aluminum-titanium laser joining are based on the brazing approach, when only aluminum side of the joint undergoes fusion and the resulting tensile strength is related to the thickness of intermetallic layer formed on titanium side. Vaidya et al. (2010) report the formation of $1.8 \mu \mathrm{m}$ thick intermetallic layer at the interface between U-shaped AA6065 plate and Ti6Al4V sheet welded by laser in conduction mode (without keyhole formation). 
In this case, the tensile strength of the junction was found superior to the resistance of aluminum alloy: the fracture happened at Al side. Chen et al. (2011) studied laser brazing in groove configuration with Si-containing filler wire and reported the beneficial effect of $\mathrm{Ti}_{7} \mathrm{Al}_{5} \mathrm{Si}_{12}$ on depressing the growth of brittle $\mathrm{Al}_{3}$ Ti phase. The fracture mode and tensile strength were depending on linear energy supply.

Laser welding in keyhole mode associated with butt configuration is less studied and is considered as difficult because of the problem of mixing between melted aluminum and titanium. The possibility to work in keyhole mode is of important technological interest as it allows to reduce the time of joint preparation (no groove machining) and has less parameters to control comparing to filler brazing (like the continuity of filler debit and precision of wire positioning) which makes it easier to obtain reproducible and stable results. In butt configuration, the shift of the laser beam from the joint line is considered as a key parameter for successful joining. Kreimeyer et al. (2005) reported the successful joining of AA6016 to Ti6Al4V with $\mathrm{CO}_{2}$ laser shifted at $0.3-0.5 \mathrm{~mm}$ to titanium side. In this case, aluminum side is only slightly melted due to its high thermal diffusivity, and $80 \%$ of the strength of AA6016 can be attained. Majumdar et al. (1997) studied $\mathrm{CO}_{2}$ laser welding of Ti6Al4V to aluminum alloy with offset to titanium side and reported the formation of the cracks in the fusion zone containing TiAl and $\mathrm{Al}_{3} \mathrm{Ti}$ phases. The insert of $\mathrm{Nb}$ foil barrier allowed suppressing $\mathrm{Al}-\mathrm{Ti}$ intermetallic formation and so enhance tensile strength from 57 to $120 \mathrm{MPa}$. Song et al. (2013) studied the influence of laser beam offset on the thickness of Al-Ti intermetallic layer between Ti6Al4V and A6061. Contrarily to Kreimeyer et al. (2005) and Majumdar et al. (1997), the shift of laser beam to aluminum side has been studied. The optimal welding conditions ( $1 \mathrm{~mm}$ offset for $4 \mathrm{~kW}$ laser power and $4 \mathrm{~m} / \mathrm{min}$ scanning speed) resulted in $0.26 \mathrm{~mm}$ thick intermetallic layer and the average tensile strength about $64 \%$ of aluminum alloy.

The state of art of $\mathrm{Al} / \mathrm{Ti}$ keyhole laser welding gives some contradictory indications concerning the optimal laser offset from joint line, and also it can be noticed that authors work at relatively low welding speed and use mainly $\mathrm{CO}_{2}$ laser. The use of higher welding rates $(>4 \mathrm{~m} / \mathrm{min})$ would minimize the interdiffusion between the melted materials and reduce the development of brittle intermetallic zones.

In present study, the weldability of Ti6Al4V/AA5754 dissimilar couple using high power Yb:YAG laser (up to $6 \mathrm{~kW}$ ) and high welding rates (up to $12 \mathrm{~m} / \mathrm{min}$ ) is explored. The effect of linear energy supply and beam offset to the joint line on the weld morphology, microstructure and mechanical properties is studied with use of experimental design approach.

\section{Experimental procedures}

\subsection{Materials}

Two millimeter thick aluminum alloy AA5754 and $2 \mathrm{~mm}$ thick Ti6Al4V alloy were used as raw materials. Their chemical composition and several properties are given in Table 1.

\subsection{Welding method}

The welding experiments were carried out in a key-hole mode using by Yb:YAG laser with maximal beam power of $6 \mathrm{~kW}$ and spot diameter of $600 \mu \mathrm{m}$. The laser beam was focused at top surface. Argon was used as shielding gas with debit of $30 \mathrm{l} / \mathrm{min}$. Top and bottom gas protection was implied. The plates were welded in butt configuration (Fig. 1).

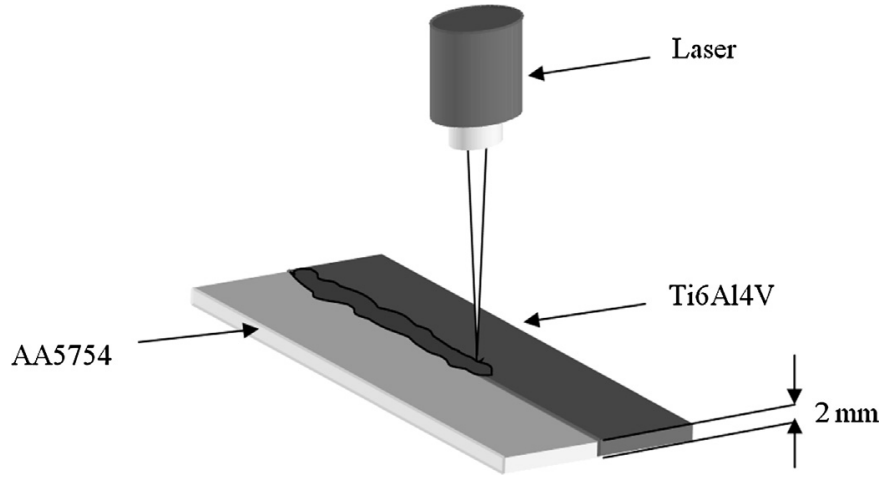

Fig. 1. Welding configuration.

Linear energy supply and beam offset were defined as key parameters for the quality of weld after preliminary experimental study. During these preliminary tests optimal range of laser power density allowing full penetration of $2 \mathrm{~mm}$ sheets was fixed. Relatively high welding speeds were fixed to maximize cooling gradient in the weld and in this way to limit the interdiffusion and mixing between aluminum ( $\mathrm{Al}$ ) and titanium (Ti)-rich liquids.

The experimental design plan has been applied to study the effect of linear energy $\left(E_{l}\right)$ and beam offset from the joint line $(\Delta x)$. During the preliminary tests, it has been found that for chosen configuration beam offset from joint line should be $<0.3 \mathrm{~mm}$ to obtain the fusion of both materials. The constant offset values and couples of parameters laser power/welding speed were used for each prepared weld (Table 2 ).

\subsection{Characterization methods}

The cross sections of the welds were polished and attacked by Keller's reagent. $20 \mathrm{~mm}$ large transversal cuts of the weld were undergone tensile test. The fractured surfaces from both sides of broken welds were examined.

The microstructure and chemical composition of the samples were studied by scanning electron microscope (JEOL) with fast EDS analyzer.

The identification of phase composition on the fractured surfaces was carried out by the X-ray diffraction (PANalytical X'Pert PRO) using a cobalt target. The scanning range of $40-110^{\circ}$ with a step scan of $0.0167^{\circ}$ and counting time of $200 \mathrm{~s}$ per step were used. The shaping of the X-ray beam by the application of appropriate slits allowed scanning whole fracture surface $\left(20 \times 2 \mathrm{~mm}^{2}\right)$. The original software package developed by Markiv and Belyavina (1997) was used to carry out the qualitative and semi-quantitative (wt.\%) phase analysis in order to determine the phase composition at fractured surfaces.

Vickers microhardness tests were carried out with load time of $15 \mathrm{~s}$ and the load of $25 \mathrm{~g}$. The UTS of the welds was evaluated at room temperature in tensile testing machine (MTS Insight $30 \mathrm{kN}$ ) at a cross head speed of $8.3 \times 10^{-5} \mathrm{~m} / \mathrm{s}$ with rectangular samples of $20 \times 100 \mathrm{~mm}$. Two tests by weld were made. The mechanical stability of the welds is characterized by linear tensile force $(\mathrm{N} / \mathrm{mm})$ because of different areas of weld cross sections and by apparent UTS (MPa) that does not takes into account the variation of thickness of the weld comparing to base materials.

For statistical analysis of obtained data experimental design method and least squares quadratic method were used (software Statistica). The relation between response parameter (like linear tensile force) and influencing parameters (like $\Delta x$ and $E_{l}$ ) is fitted mathematically (2nd degree polynomial function represented graphically, Fig. 3). The reason of mathematical fitting resides in 
Table 1

Chemical composition and some physical properties of used alloys.

\begin{tabular}{|c|c|c|c|c|}
\hline & Chemical composition (wt.\%) & $T_{\text {solidus }}(\mathrm{K})$ & $T_{\text {boiling }}(\mathrm{K})$ & UTS (MPa) \\
\hline AA5754 & Al: 93; Mg: 6; Si: $\leq 1$ & 753 & 2015 & 220 \\
\hline Ti6Al4V & $\mathrm{Ti}: 90 ; \mathrm{Al}: 6 ; \mathrm{V}: 4^{-}$ & 1923 & 3585 & 830 \\
\hline
\end{tabular}

Table 2

Experimental layout.

\begin{tabular}{|c|c|c|c|}
\hline \multirow[t]{2}{*}{$\Delta x(\mathrm{~mm})$} & \multicolumn{3}{|l|}{$E_{l}=P_{\text {laser }} / V_{s}(\mathrm{~kJ} / \mathrm{m})$} \\
\hline & 30 & 37.5 & 45 \\
\hline 0.2 (to Ti6Al4V) & $1 \mathrm{~A}: 6 \mathrm{~kW} ; 12 \mathrm{~m} / \mathrm{min}$ & $1 \mathrm{~B}: 4 \mathrm{~kW} ; 6.4 \mathrm{~m} / \mathrm{min}$ & 1C: $5 \mathrm{~kW} ; 6.6 \mathrm{~m} / \mathrm{min}$ \\
\hline 0 (centered) & $2 \mathrm{~A}: 6 \mathrm{~kW} ; 12 \mathrm{~m} / \mathrm{min}$ & $2 \mathrm{~B}: 5 \mathrm{~kW} ; 8 \mathrm{~m} / \mathrm{min}$ & $2 \mathrm{C}: 4 \mathrm{~kW} ; 5.3 \mathrm{~m} / \mathrm{min}$ \\
\hline-0.2 (to AA5754) & $3 \mathrm{~A}: 6 \mathrm{~kW} ; 12 \mathrm{~m} / \mathrm{min}$ & $3 \mathrm{~B}: 6 \mathrm{~kW} ; 9.6 \mathrm{~m} / \mathrm{min}$ & $3 \mathrm{C}: 5 \mathrm{~kW} ; 6.6 \mathrm{~m} / \mathrm{min}$ \\
\hline
\end{tabular}

showing the tendency of evolution of response parameter (like linear tensile force) in function of two varying operational parameters.

\section{Results and discussion}

\subsection{General observation and macro properties}

For all tested operational parameters (Table 2) it can be noticed that resulting weld consists of two easy discernible mixing zones: one rich in aluminum and another rich in titanium, separated by well localized contact interface (Fig. 2). The combination of high laser power and rapid scan speed allows perform welding in capillary mode with extremely short interaction time. As there is a big mismatch in fusion temperatures of welded materials (Table 1 ), the excessive mixing between liquid phases, that is undesirable because of risk to create bulk zones of intermetallic phases, is avoided.

Three different laser beam offsets from joint line were tested: Fig. 2 presents crosscuts of several welds chosen to illustrate effect of beam position on global morphology. Fabbro (2013) demonstrated that the shape of the capillary created during continuous full penetrated laser welding is close to the diameter of focused laser stop. If we suppose capillary diameter be close to laser spot diameter $(0.6 \mathrm{~mm}), 0.2 \mathrm{~mm}$ beam offset from joint line allows almost total shift of the capillary in one of materials, when centered beam position results in capillary shared between two materials. It can be noticed that in case of $0.2 \mathrm{~mm}$ beam offset on Ti6Al4V side Tirich melted zone contains important volume defects appearing due to the trapping of the capillary and ejection of Ti-rich liquid from the melted zone; the contact interface is the thickest and contains numerous porosities (Fig. 2a).

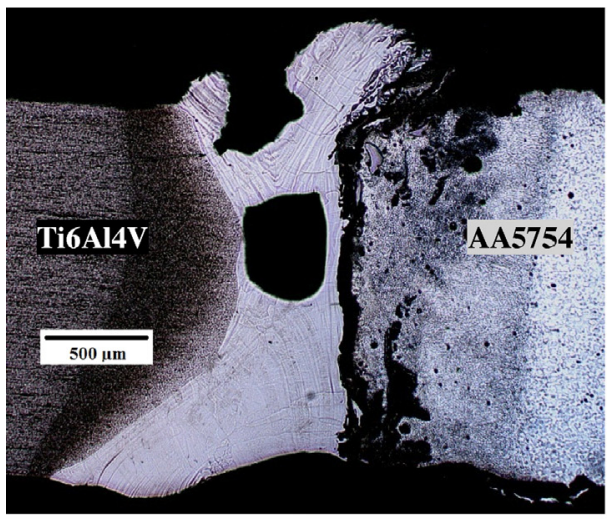

(a)

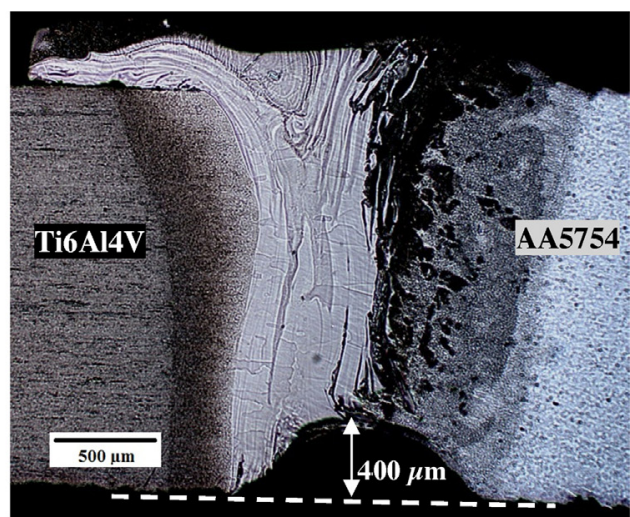

(b)

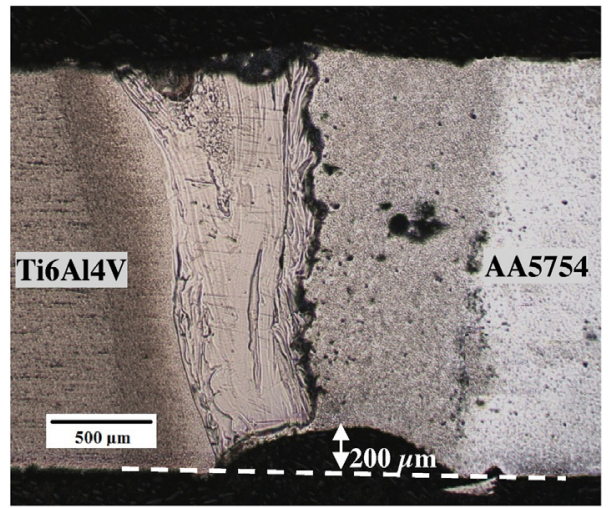

(c)

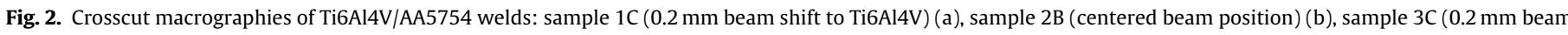
shift to AA5754) (c). 

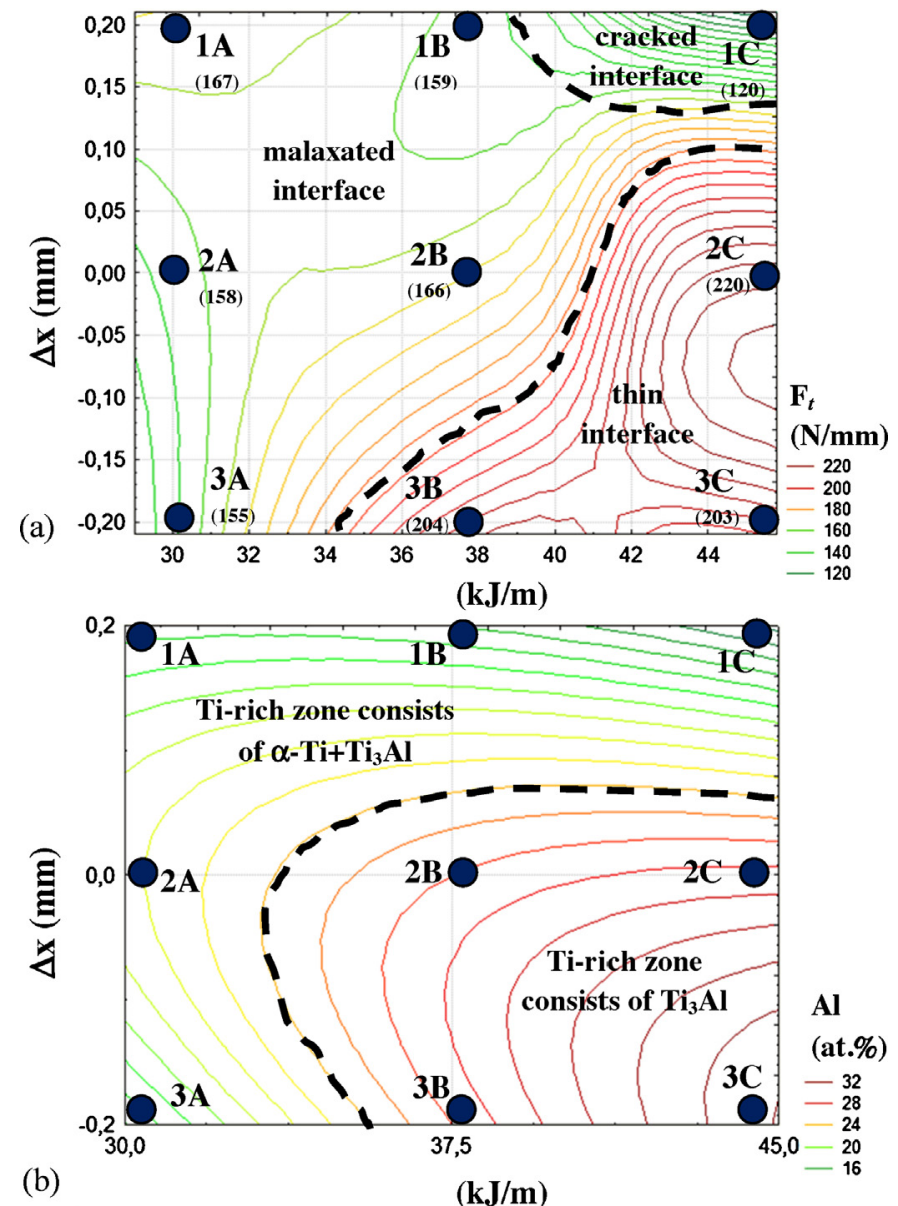

Fig. 3. Response surfaces of linear tensile force $(\mathrm{N} / \mathrm{mm})$ of the welds (a) and $\mathrm{Al}$ content (at.\%) in Ti6Al4V melted zone (b).

It can be seen that centered beam position results in reduction of weld thickness at $20 \%$ and in less violent projections of Ti-rich liquid (Fig. 2b). Also it can be noticed that contact interface is often composed by numerous intimely mixed Ti and Al-rich lamellas. It can be supposed that such mixed interface is formed when Ti and Al-rich flows of different speed, density and viscosity collide behind the capillary. Tomashchuk et al. (2010) observed similar phenomenon for $\mathrm{Cu}-\mathrm{Fe}$ dissimilar couple. This hypothesis is confirmed by observation that mixed interface does not form when welding speed is $\leq 5.3 \mathrm{~m} / \mathrm{min}$.

Finally, beam shift toward AA5754 side (Fig. 2c) results in accurate weld profile with no volume defects and no projections, reduction of thickness $\leq 10 \%$ and thin contact interface. It can be concluded that positioning of the capillary in AA5754 side is the best choice: because of lower fusion temperature, melted zone at AA5754 side remains in liquid state longer, which allows closing the capillary correctly and avoiding gas trapping in solidified material as it happens in case when vaporization of titanium is involved.

The analysis of operational parameters window with respect to linear tensile force $\left(F_{t}\right)$ of the weld (Fig. 3a) indicates that there is no important variation of tensile behavior (excepting case $1 \mathrm{C}$ discussed below) and that maximal linear tensile force can be attained with combination of beam offset on AA5754 side and use of high linear energy. The maximal tensile force of the welds is about $220 \mathrm{~N} / \mathrm{mm}$ or, roughly, $120 \mathrm{MPa}$ of apparent UTS, which corresponds to about 60\% UTS of AA5754 weld. The shift of laser beam toward Ti6Al4V leads to decrease of UTS for all tested linear energies. Maximal linear energy associated with beam offset forwards Ti6Al4V side leads to worst result of $F_{t}=120 N / m m$ (sample $1 C$,
Fig. 2a). In this case, the mixing of Ti with $\mathrm{Al}$ is maximal. All intermediate conditions lead to linear tensile force about $160 \mathrm{~N} / \mathrm{mm}$.

The global chemical composition of aluminum rich and titanium rich melted zones determined by EDS analysis indicates very limited penetration of $\mathrm{Ti}$ in Al-rich melted zone ( $\leq 5 \mathrm{at} . \% \mathrm{Ti}$ ), when Ti-rich melted zone contains up to 33 at.\% of Al (Fig. 3b), which corresponds to the formation of the mixture of $\alpha-\mathrm{Ti}$ and $\mathrm{Ti}_{3} \mathrm{Al}$ (when $\mathrm{Al} \leq 20$ at.\%) or only $\mathrm{Ti}_{3} \mathrm{Al}$ (when $\mathrm{Al}>20$ at.\%). The analysis of response surface for chosen window of operational parameters indicates that increase of linear energy combined with displacement of laser beam to AA5754 side increases the quantity of Al dissolved in Ti-rich melted zone.

Such difference in interpenetration of $\mathrm{Al}$ and $\mathrm{Ti}$ can be explained by mismatch in thermophysical properties and by thermodynamic factor. As Ti6Al4V has much higher fusion temperature than AA5754 (Table 1), the volume of melted titanium is much smaller than volume of melted aluminum. Because of high solidification rates proper to laser welding $(>103 \mathrm{~K} / \mathrm{s})$, the convective mixing between melted materials is limited and the main solidification process, due to the classification of Boettinger and Coriell (1986), is the local equilibrium at solid-liquid interface.

In their study of thermodynamic properties of $\mathrm{Al}-\mathrm{Ti}$ system Kattner et al. (1992) show that the solidification starts from $\beta$-Ti phase and $(\beta-\mathrm{Ti})$ solid solutions. The important migration of $\mathrm{Al}$ in Ti-rich melted zone is determined by lower Gibbs energy of $(\beta-\mathrm{Ti})$ formation comparing to that of coexisting Al-rich liquids. Also, diffusion coefficient of $\mathrm{Al}$ in liquid titanium overpasses diffusion coefficient of $\mathrm{Ti}$ in liquid aluminum: for example, at $2023 \mathrm{~K}$, $D_{\mathrm{Al}}(\mathrm{L}-\mathrm{Ti})=7.57 \times 10^{-8} \mathrm{~m}^{2} / \mathrm{s}$ accordingly to Du et al. (2003) and $D_{\mathrm{Ti}}(\mathrm{L}-\mathrm{Al})=2.15 \times 10^{-8} \mathrm{~m}^{2} / \mathrm{s}$ accordingly to Blacha et al. (2014). Consequently, during the partition of the elements across the contact interface, the concentration of $\mathrm{Al}$ in Ti-rich zone becomes higher than concentration of Ti in Al-rich zone. During the solidification, Ti-rich melted zone slowly becomes more and more depleted in Ti. Consequently, a number of ( $\beta$-Ti) solid solutions having more and more high content of $\mathrm{Al}$ is formed. Then, during further cooling of Ti-rich zone these ( $\beta$-Ti) solutions are transformed in $\alpha$-Ti and/or $\mathrm{Ti}_{3} \mathrm{Al}$ depending on $\mathrm{Al}$ content.

From the other side, the migration of $\mathrm{Ti}$ in $\mathrm{Al}$-rich melted zone is not promoted by thermodynamics of Al-Ti system. Kattner et al. (1992) show that $\mathrm{Al}_{3} \mathrm{Ti}$ is the last solidified phase, which is coherent with shrinkage defects observed in sample $1 \mathrm{C}$ where this phase is present in high quantity, as it will be discussed in next sections. Moreover, aluminum, having higher thermal diffusivity, prevents drops of liquid titanium from dissolution as they quickly reach solidus temperature. Consequently, the most part of titanium penetrated at $\mathrm{Al}$ side is found in form of isles (for example, Fig. 7a) situated next to contact interface.

The hardness measurements performed at middle-height of transversal cross sections showed close values for all operational conditions (Fig. 4). The hardness of melted zone rich in titanium is superior comparing to Ti6Al4V (from $415 \mathrm{HV}$ to $450-550 \mathrm{HV}$ depending on quantity of $\mathrm{Ti}_{3} \mathrm{Al}$ formed in Ti-rich melted zone) and arises accordingly to the distribution of $\mathrm{Al}$ in Ti-rich melted zone. Al-rich melted zone shows microhardness close to that of AA5754 $(\approx 100 \mathrm{HV})$. Rare isles of $\mathrm{Ti}_{3} \mathrm{Al}$ found in Al-rich melted zone show hardness up to $550 \mathrm{HV}$. The contact zone has maximal hardness that arises up to 600-700 HV. Sample 1C (Fig. 4a) shows high hardness over large region corresponding to thick contact zone, which explains low linear tensile force of this particular weld. The samples having higher tensile strength show the presence of brittle zones over very limited thickness (Fig. 4b and c).

During tensile tests, the contact interface appeared to be the weakest part of the weld, so the next studies were dedicated to the morphology of this zone and fractography of the welds. 

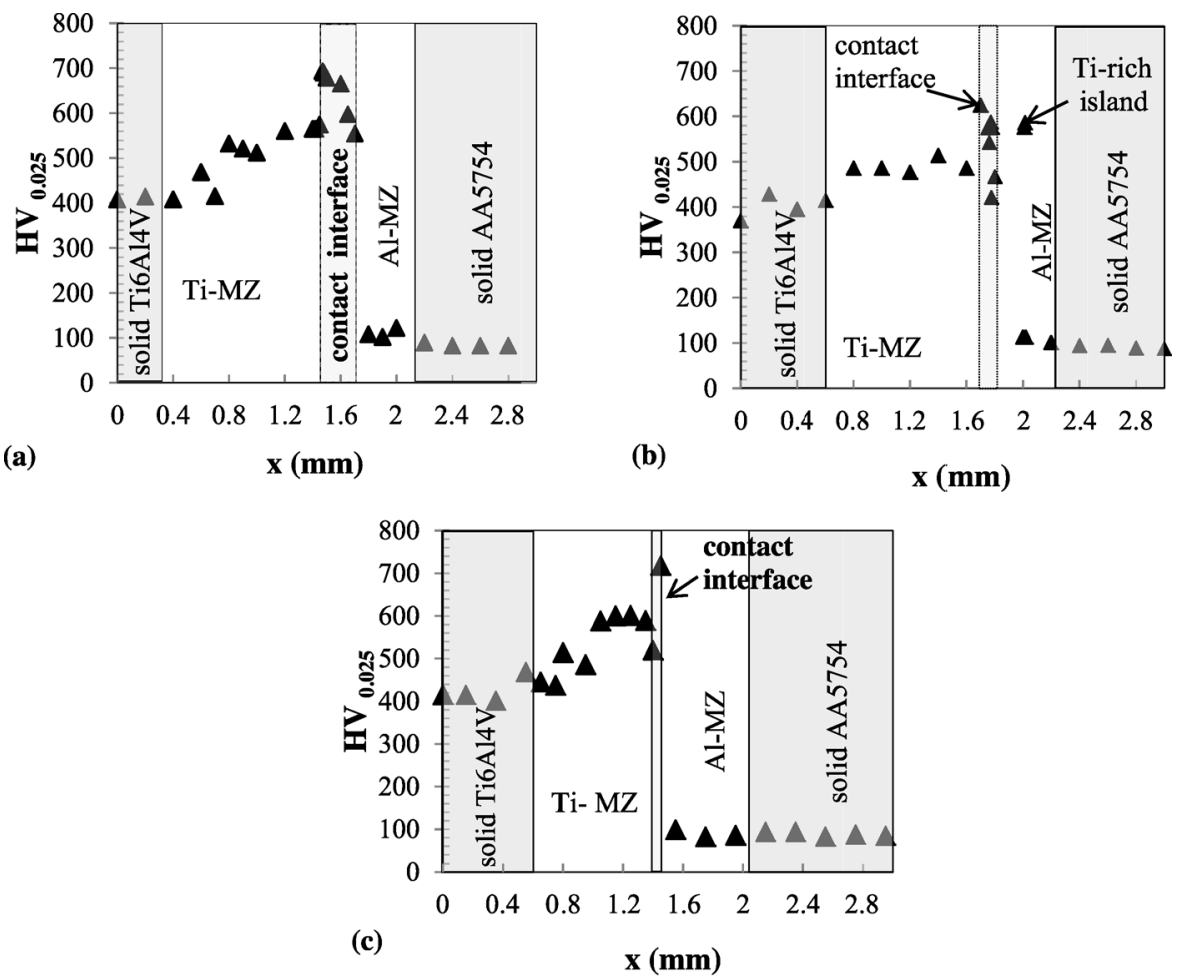

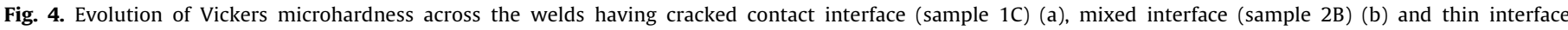
(sample 3C) (c).

\subsection{Structure of dissimilar interfaces}

During microscopic observations of contact zone, three principal morphologies could be identified: thin interface (Fig. 5); cracked interface (Fig. 6) and so called malaxated interface (Fig. 7). For each case, topography SEM image and X-ray mapping are provided and the phase content of different zones estimated from punctual EDS analysis is indicated. The morphology and phase content of these interfaces are determined by velocity field of contacting Al-rich and Ti-rich flows and by interdiffusion of the components in liquid phase under action of chemical potential.

It can be seen (Fig. 3a) that the welds presenting thin contact interface are all situated in the corner of experience design plan that tends to beam shift toward aluminum combined with maximum linear energy (samples 2C, 3B and 3C) and have close linear tensile force values which are maximal over explored zone of operational parameters. The X-ray mapping and EDS analysis of this type of interface (Fig. 5) shows narrow zone of composition close to TiAl that is almost not affected by convection at micro level. The thickness of the interface varies in a small range: 5.4, 8.6 and $18.6 \mu \mathrm{m}$ for samples $2 \mathrm{C}, 3 \mathrm{~B}$ and $3 \mathrm{C}$ respectively.

The cracked interface (Fig. 6) is found in standalone case $1 \mathrm{C}$ when $0.2 \mathrm{~mm}$ beam shift toward titanium is combined with maximal linear energy. Under these conditions melting of titanium is enhanced and more pronounced convective mixing between $\mathrm{Al}-$ rich and Ti-rich melted zones becomes possible. Malicrot (2008) showed that during continuous laser welding cooling gradient can reach $10^{4} \mathrm{~K} / \mathrm{s}$. During the rapid cooling of the melt the solidification of this mixing zone results in formation of $190-300 \mu \mathrm{m}$ thick intermetallic layer formed by regions of $\mathrm{TiAl}+\mathrm{TiAl}_{2}, \mathrm{TiAl}$ and $\mathrm{Al}_{3} \mathrm{Ti}$. As the growth of these phases by diffusion in solid state is suppressed by strong cooling gradient, local phase content is determined only by action of convective forces and chemical affinity. The intermetallic layers of such thickness are very brittle that traduces by low linear tensile force of the weld: only $120 \mathrm{~N} / \mathrm{mm}$ or less, depending on local accumulation of defects. Numerous cracks crossing TiAl and $\mathrm{Al}_{3} \mathrm{Ti}$ zones are visible (Fig. 6). It can be supposed that they formed immediately after the solidification of the weld as result of local accumulation of residual stress. As it is shown below (Fig. 9a), the zones of $\mathrm{Al}_{3} \mathrm{Ti}$ contain voids that must have formed because of the shrinkage of the melt and then serve as the initiators of cracks.

The rest of the welds present the interface very affected by convection (Fig. 7). Thin zones of $\mathrm{Ti}_{3} \mathrm{Al}$ (of which Ti-rich melted zone is composed) are found mixed with thin TiAl layers; standalone $\mathrm{Al}_{3} \mathrm{Ti}$ zones are also present. Ti is present at AA5754 side in form of $\mathrm{Ti}_{3} \mathrm{Al}$ isles. It can be seen that solidification occurred very quickly after the mixing of two liquid phases, as the interdiffusion process had no time to develop, comparing to case $1 \mathrm{C}$. The total thickness of malaxated interfaces varies from 90 to $245 \mu \mathrm{m}$, but it has no direct correlation with linear tensile force which stays close to $160 \mathrm{~N} / \mathrm{mm}$.

It can be concluded that tensile strength of the welds is determined by morphology of contact interface. The minimization of interaction between the components allows increase tensile strength. From one side, it can be attained by positioning the beam (and so, the capillary) in AA5754 side (samples 3B and 3C, Fig. 3a). From other side, the effect of welding speed also can be seen. In spite of beam shift to AA5754 side the malaxated contact interface was formed in the sample 3A because of high welding speed ( $12 \mathrm{~m} / \mathrm{min}$ ) which enhances convection phenomena between contacting in melted zones. At the same time, for sample $2 \mathrm{C}$ having centered beam position, the formation of thin interface still took place, as welding speed was only of $5.3 \mathrm{~m} / \mathrm{min}$. Welding speed appears to be more pertinent parameter than linear energy. The isle of optimal parameters corresponding to the formation of thin interface is situated in the zone of high linear energies (Fig. 3a), but true reason appears to be the reducing of welding speed comparing to the welds associated with low linear energy (Table 2). 


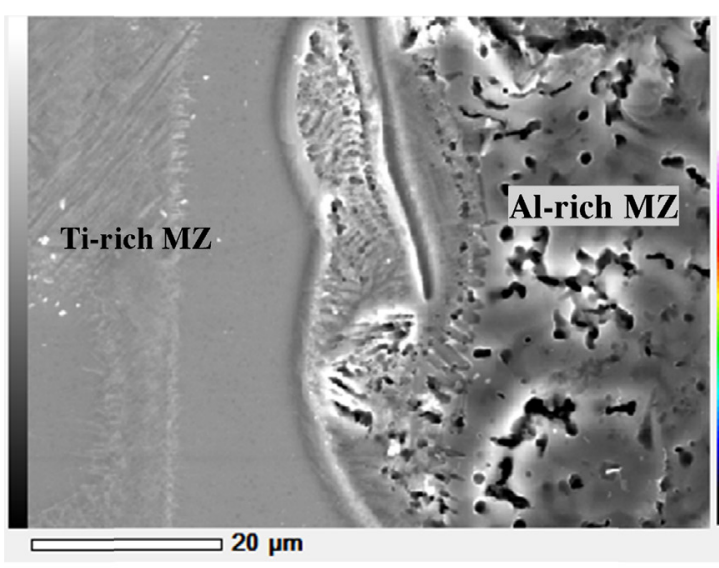

(a)

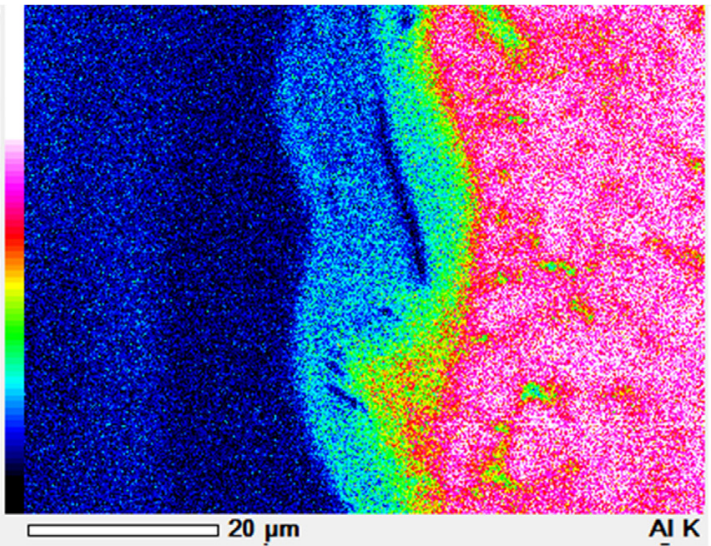

(b)

Fig. 5. SEM image (a) and X-ray Al-k map (b) of thin diffusive interface between Ti and Al-rich melted zones (sample 3C).

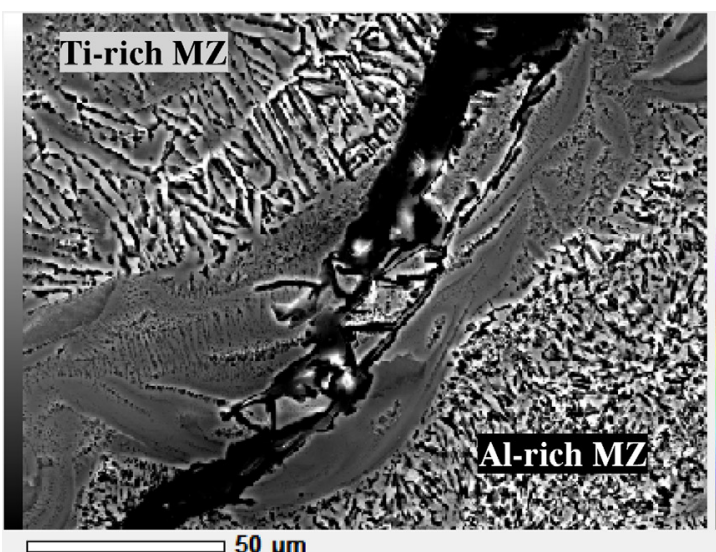

(a)

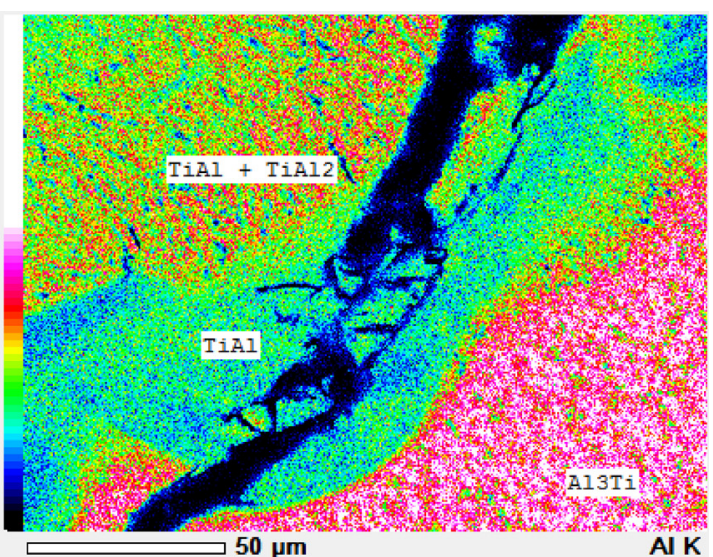

(b)

Fig. 6. SEM image (a) and X-ray Al-k map (b) of fractured diffusive interface between Ti and Al-rich melted zones (sample 1C).

\subsection{Fractography of dissimilar interfaces}

In order to understand the influence of contact interface composition on the tensile strength of the welds, the fracture surfaces of the welds obtained after tensile test were studied by EDS and XRD. Under all operational conditions the fracture involved contact interface situated between $\mathrm{Al}$ and Ti-rich melted zones. It was found that three morphologies of contact interfaces result in three different modes of fracture (illustrated by SEM topography images, Figs. 8-10).

The samples having thin contact interface (sample 3C, Fig. 8) present fracture surfaces composed by zones of $\mathrm{Al}$ and zones containing various proportions between $\mathrm{Ti}$ and $\mathrm{Al}$. EDS analysis of $\mathrm{Al}$ zones (Fig. 8a) showed the composition identical to that of AA5754,

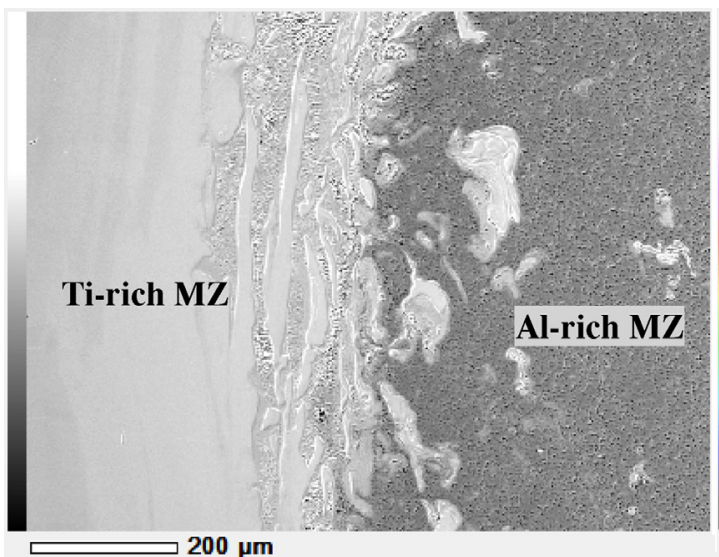

(a)

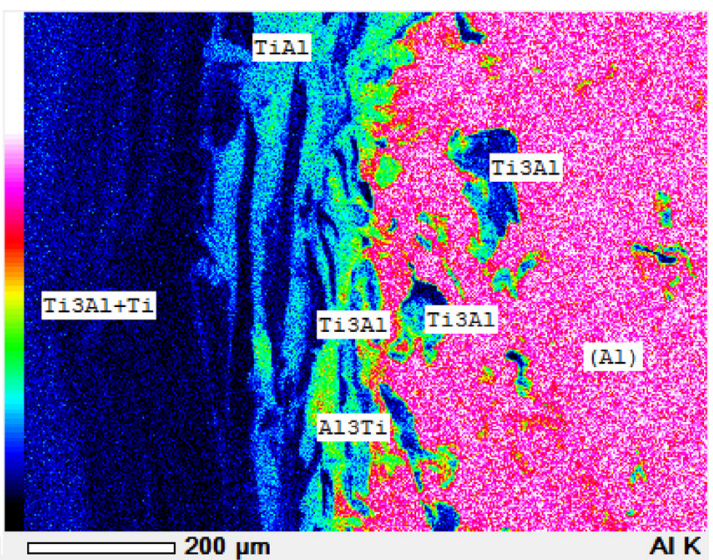

(b)

Fig. 7. SEM image (a) and X-ray Al-k map (b) of malaxated diffusive interface between Ti and Al-rich melted zones (sample 2B). 


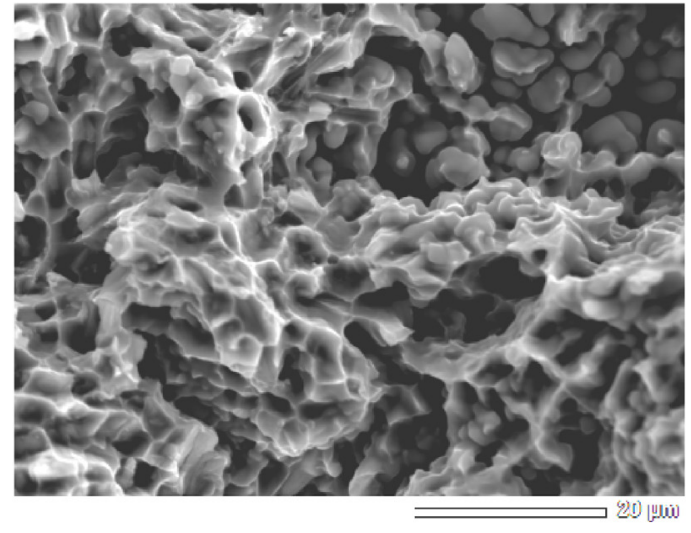

(a)

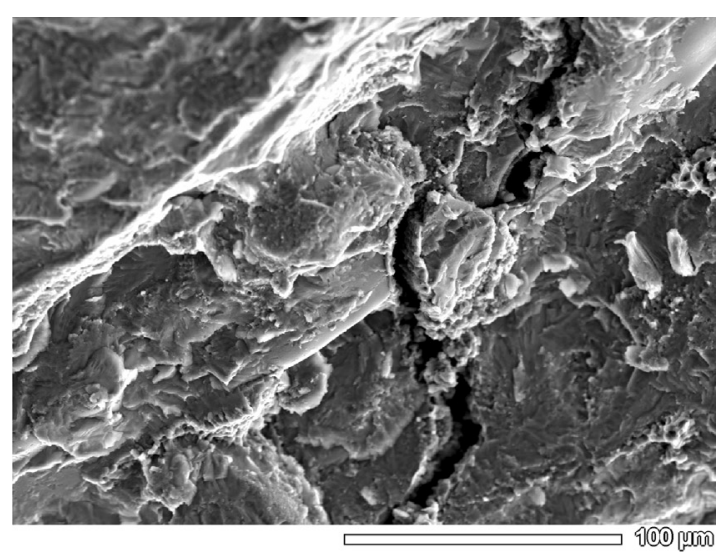

(b)

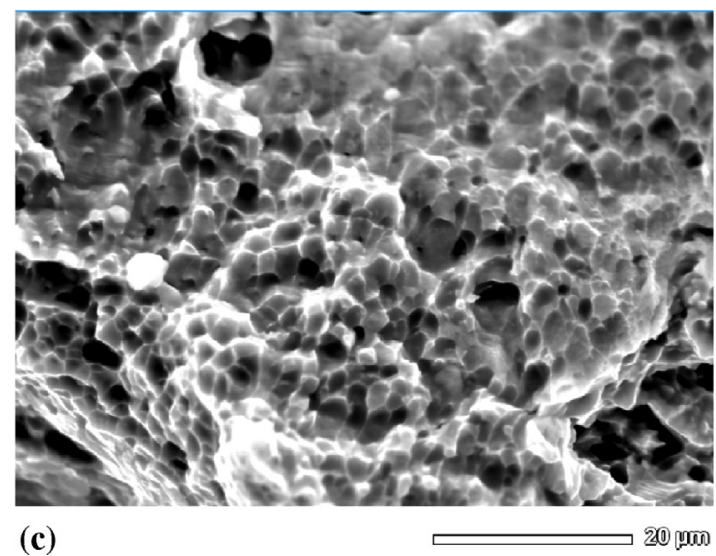

(c)

Fig. 8. SEM images of fracture surfaces of sample 3C: Al-rich zone (a) and TiAl zone (b); fractured surface of A5754/A5754 weld, provided for comparison (c).

moreover, the fracture surfaces of these zones present the aspect identical to the surface of broken AA5754/AA5754 weld (Fig. 8c). The zones containing both $\mathrm{Ti}$ and $\mathrm{Al}$ (Fig. $8 \mathrm{~b}$ ) present cleavage fracture mode and contain mixtures of different intermetallics, where TiAl phase dominates. It can be supposed that the crack initiates in thin contact interface, which splits in two, because we don't see the zones of $\mathrm{Ti}_{3} \mathrm{Al}$ situated at titanium-side of the contact interface, and then propagates in neighboring Al-rich melted zone. High tensile strength of such welds can be attributed to higher mechanical stability and to more ductile behavior of $\mathrm{Al}$ zones comparing to brittle intermetallic zones.
The fracture surfaces of sample $1 \mathrm{C}$ (having cracked contact interface) consists mainly of Al-rich zones, but unlike previous case their composition corresponds to $\mathrm{Al}_{3} \mathrm{Ti}+\mathrm{Al}$. Numerous voids containing dendrites of $\mathrm{Al}_{3} \mathrm{Ti}$ can be observed (Fig. 9a). Next to them the zones of TiAl broken in cleavage mode are found (Fig. 9b). Low linear tensile force of sample $1 \mathrm{C}$ comparing to $3 \mathrm{C}$ is determined by replacement of ductile $\mathrm{Al}$-rich zones by fragile $\mathrm{Al}_{3} \mathrm{Ti}$-rich zones containing voids.

The broken surfaces of the samples having malaxated contact interface (like sample 1C) show Al zones identical to AA5754 which underwent intergranular fracture next to $\mathrm{TiAl}$ and $\mathrm{Al}_{3} \mathrm{Ti}$ zones

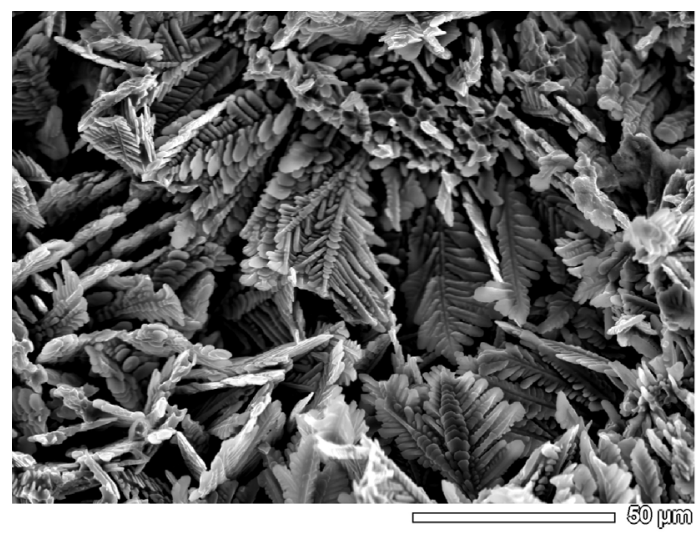

(a)

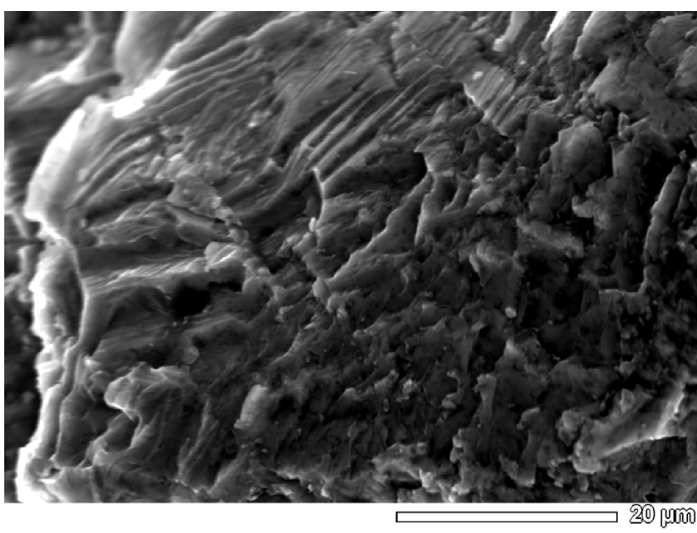

(b)

Fig. 9. SEM images of fracture surface of sample 1C: Al-rich zone containing voids filled with $\mathrm{Al}_{3} \mathrm{Ti}$ dendrites (a); TiAl zone (b). 


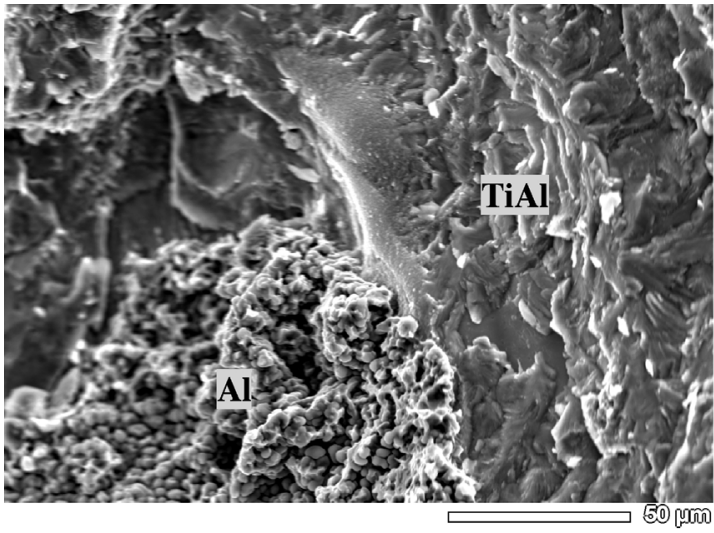

(a)

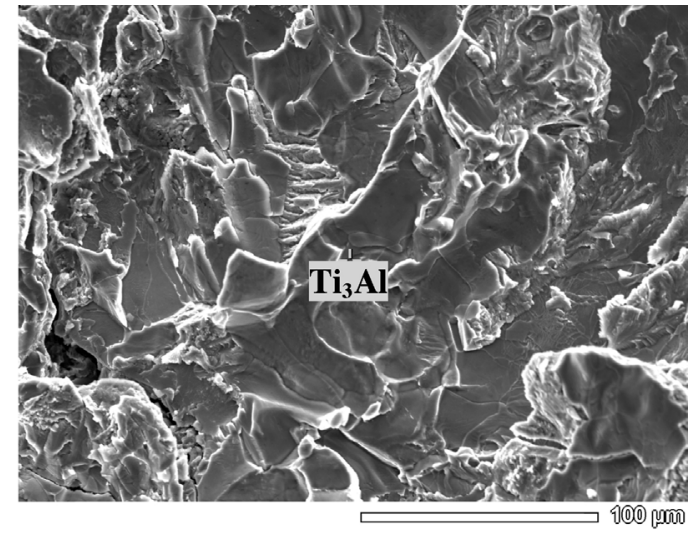

(b)

Fig. 10. SEM images of fracture surface of sample 2B: malaxated Al-rich and TiAl-rich zones (a); $\mathrm{Ti}_{3} \mathrm{Al}$ zone (b).

broken in cleavage mode (Fig. 10a). But also we found regions of $\mathrm{Ti}_{3} \mathrm{Al}$ broken in cleavage mode (Fig. 10b). The presence of $\mathrm{Ti}_{3} \mathrm{Al}$ regions as well as $\mathrm{Al}, \mathrm{TiAl}$ and $\mathrm{Al}_{3}$ Ti regions corresponds to the propagation of the crack between the intermalaxated layers of $\mathrm{Ti}_{3} \mathrm{Al}, \mathrm{TiAl}$ and Al which form contact interface (compare with Fig. 7).

In order to relate the phase content of fractured surfaces with tensile behavior of the welds, they underwent XRD analysis with semi-quantitative estimation of phase content. It is found that the fractured surfaces both from AA5754 and Ti6Al4V sides have very close composition (the typical XRD profile of two broken sides of the same weld is shown at Fig. 11a). $\mathrm{TiAl}, \mathrm{Al}_{3} \mathrm{Ti}$ and $\mathrm{Al}$ phases were identified for all samples, but the proportion between them varies (Fig. 11b and c). Fractured surfaces almost do not contain $\alpha$-Ti (as Ti-rich melted zone is composed mainly by $\mathrm{Ti}_{3} \mathrm{Al}$ ). Low quantities of $\mathrm{Ti}_{3} \mathrm{Al}$ are also present, especially when the crack propagates at malaxated interface.

It was found that in the samples having thin contact interface, like 3C, Al dominates on both broken surfaces, which means that the fracture is situated mainly in Al-rich melted zone; however, sometimes it crosses contact interface and even touches Ti-rich melted

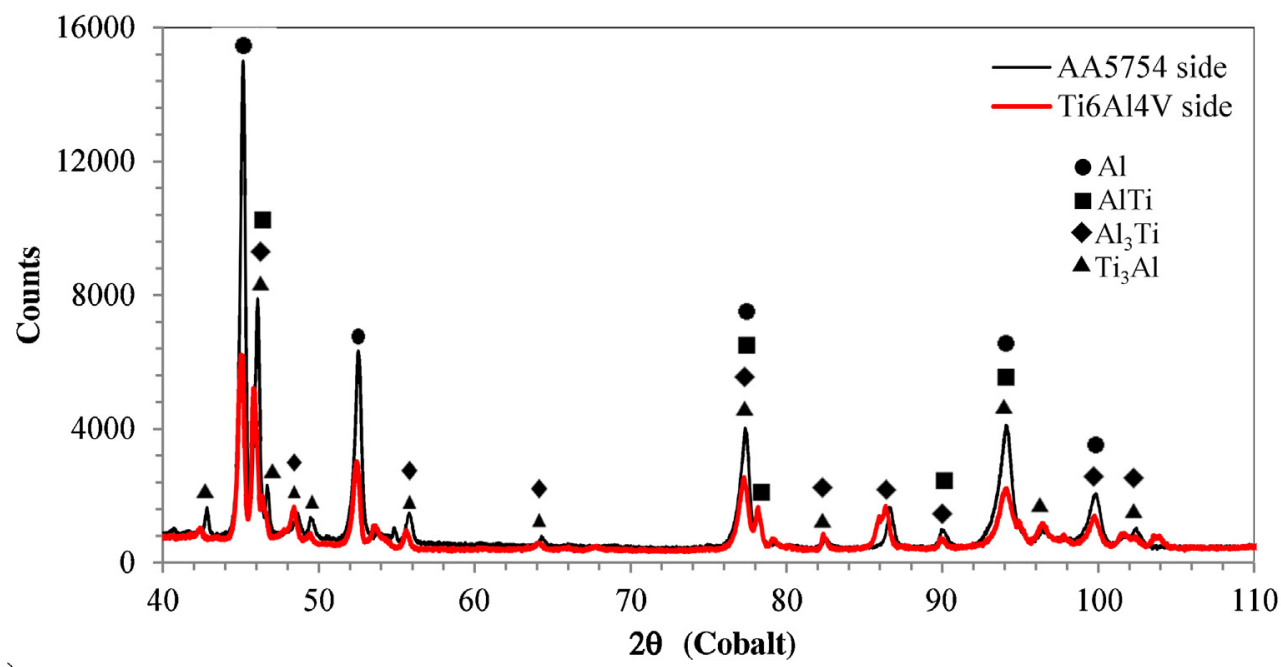

(a)

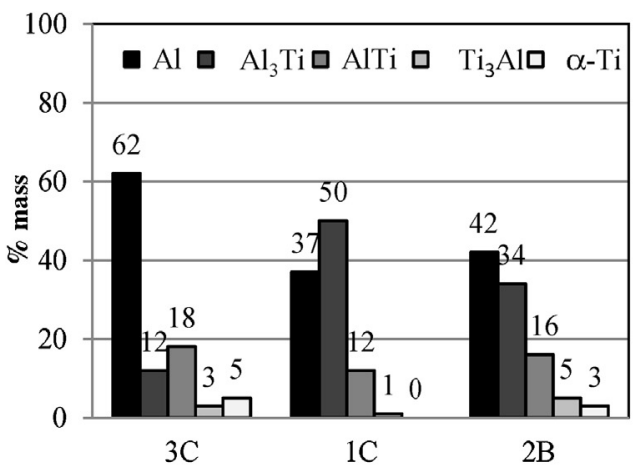

(b)

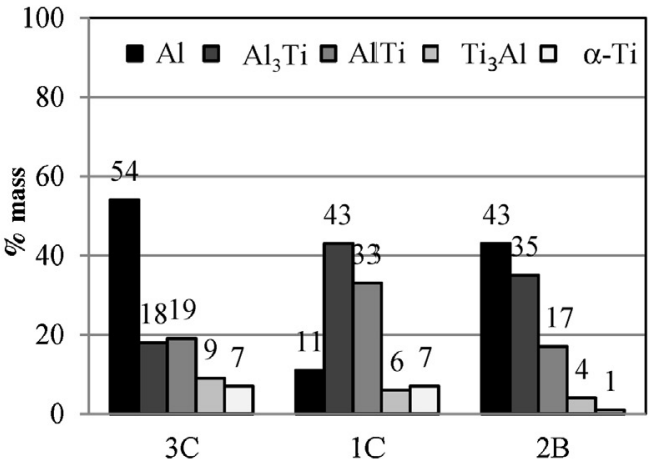

(c)

Fig. 11. XRD of the sample $3 \mathrm{C}$ (a); estimated quantity of phases identified at the broken surfaces of the samples 1C, 3C and 2B: AA5754 side (b) and Ti6Al4V side (c). 
zone as some quantities of intermetallic phases also are present. Brittle $\mathrm{Al}_{3} \mathrm{Ti}$ phase is found in low quantities. Contrasting situation is observed for sample $1 \mathrm{C}$ having cracked interface: the dominating phase on both sides is $\mathrm{Al}_{3} \mathrm{Ti}$, which is in correspondence with presence of voids containing $\mathrm{Al}_{3} \mathrm{Ti}$ dendrites (Fig. 9a). Pure $\mathrm{Al}$ is present in very low quantity at Ti6Al4V side of the fracture, but the amounts of $\alpha$-Ti and $\mathrm{Ti}_{3} \mathrm{Al}$ also are very low. So, it can be concluded that fracture propagates mainly inside contact interface starting from initially present voids and cracks formed during solidification. The samples with mixed contact interface like $2 \mathrm{~B}$ present intermediate case: on both sides important amounts of $\mathrm{Al}$ and $\mathrm{Al}_{3} \mathrm{Ti}$ can be found as well as $\mathrm{Ti}_{3} \mathrm{Al}$. Here fracture is shared between Al-rich melted zone and malaxated layers of intermetallics forming contact interface with Ti-rich melted zone.

\section{Conclusions}

The possibility of direct high speed Yb:YAG laser welding of aluminum alloy AA5754 to titanium alloy Ti6Al4V in keyhole mode has been explored.

- Rapid thermal cycle enables to limit the interaction zone between Al-rich and Ti-rich liquids to the contact interface composed by intermetallic phases of Al-Ti system. Tensile properties and mode of fracture of obtained welds are determined by the morphology and phase composition of contact interface.

- Shift of laser beam to AA5754 side promotes the formation of thin contact interface providing maximal tensile strength: $120 \mathrm{MPa}$ of apparent UTS or about $60 \%$ of UTS of AA5754 weld. However, this interface can be maintained only if welding speed does not exceed $10 \mathrm{~m} / \mathrm{min}$, otherwise thicker interface affected by convection is formed.

- Shift of laser beam to Ti6Al4V side promotes the formation of thick contact interface rich in $\mathrm{Al}_{3} \mathrm{Ti}$ phase, containing cracks and voids and creates the risk of important volume defects.

- In case of centered laser beam position or shift to Ti6Al4V even speed of $5 \mathrm{~m} / \mathrm{min}$ is enough to create thick interface $(90-300 \mu \mathrm{m})$ affected by convection, in this case tensile strength drops down to $30-36 \%$ of AA5754 weld.

- Different morphologies of contact interface result in different modes of fracture: in case of thin interface fracture involves both Al-rich melted zone and intermetallic layers, when in case of thick interfaces it occurs mainly inside intermetallic layers.

\section{Acknowledgements}

This work was supported by the French program Institut CARNOT Arts in the frame of the ATTILA project.

The authors wish to thank Pr. Nadezhda Belyavina (Department of Physics, Taras Shevchenko University, Kiev, Ukraine) for her precious help in processing and interpretation of XRD spectra and to research engineer Melanie Duband (Laboratoire Interdisciplinaire Carnot de Bourgogne, Université de Bourgogne) for her contribution in welding experiments.

\section{References}

Blacha, L., Mizera, J., Folęga, P., 2014. The effects of mass transfer in the liquid phase on the rate of aluminum evaporation from the Ti-6Al-7Nb alloy. Metalurgija 53, 51-54.

Boettinger, W.J., Coriell, S.R., 1986. Microstructure formation in rapidly solidified alloys. Sci. Technol. Undercooled Melt 144, 81-109.

Chang, S.Y., Tsao, L.C., Lei, Y.H., Mao, S.M., Huang, C.H., 2012. Brazing of 6061 aluminum alloy/Ti-6Al-4 V using Al-Si-Cu-Ge filler metals. J. Mater. Process. Technol. 212, 8-14.

Chen, S., Li, L., Chen, Y., Dai, J., Huang, J., 2011. Improving interfacial reaction nonhomogeneity during laser welding-brazing aluminum to titanium. Mater. Des. 32 4408-4416.

Du, Y., Chang, Y.A., Huang, B., Gong, W., Jin, Z., Xu, H., Yuan, Z., Xie, F.-Y., 2003. Diffusion coefficients of some solutes in fcc and liquid Al: critical evaluation and correlation. Mater. Sci. Eng., A 363, 140-151.

Ege, E.S., Inal, O.T., 2000. Stability of interfaces in explosively welded aluminum titanium laminates. J. Mater. Sci. Lett. 19, 1533-1535.

Fabbro, R., 2013. Developments in Nd-Yag laser welding. In: Katayama, S. (Ed.), Handbook of Laser Welding Technologies. Woodhead Publishing Limited, Oxford, pp. 47-72, 2013.

Fuji, A., Kimura, M., North, T.H., Ameyama, K., Aki, M., 1997. Mechanical properties of titanium-5083 aluminum alloy friction joints. Mater. Sci. Technol. 13, 673-678.

Jiangwei, R., Yajiang, L., Tao, F., 2002. Microstructure characteristics in the interface zone of Ti/Al diffusion bonding,. Mater. Lett. 56, 647-652.

Kattner, U.R., Lin, J.C., Chang, Y.A., 1992. Thermodynamic assessment and calculation of the Ti-Al system. Metall. Trans. A 23A, 2081-2090.

Kreimeyer, M., Wagner, F., Vollertsen, F., 2005. Laser processing of aluminum-titanium-tailored banks. Opt. Lasers Eng. 43, 1021-1035.

Majumdar, B., Galun, R., Weisheit, A., Mordike, B.L., 1997. Formation of crack-free joint between Ti alloy and $\mathrm{Al}$ alloy by using a high-power $\mathrm{CO}_{2}$ laser. J. Mater. Sci. 32, 6191-6200.

Malicrot, A., 2008. Etude de la formation et des propriétés physiques des zones fondues dans le cas de l'assemblage du tantale avec l'alliage de titane TA6V. Université de Bourgogne, France (Ph.D. thesis).

Markiv, V., Belyavina, N., Hardware and software for investigation of XRD spectra of polycrystalline materials, In: Proceedings of the Second International Scientific Conference of Engineering and Functional Materials, 14-16 October 1997, L'viv, Ukraine, 260.

Mathieu, A., Pontevicci, S., Viala, J.-C., Cicala, E., Matteï, S., Grevey, D., 2006. Lase brazing of a steel/aluminum assembly with hot filler wire ( $88 \% \mathrm{Al}, 12 \% \mathrm{Si})$,. Mater. Sci. Eng. A 435-436, 19-28.

Okamura, H., Aota, K., 2004. Joining of dissimilar materials with friction stir welding. Weld. Int. 18, 852-860.

Raghavan, V., 2005. Aluminum-titanium. J. Phase Equilib. Diffus. 26, 171-172.

Sambasiva Rao, A., Madhusudhan Reddy, G., Satya Prasad, K., 2011. Microstructure and tensile properties of dissimilar metal gas tungsten arc welding of aluminum to titanium alloy. Mater. Sci. Technol. 27, 65-70.

Sierra, G., Peyre, P., Deschaux-Beaume, F., Stuart, D., Fras, G., 2007. Steel to aluminum key-hole laser welding. Mater. Sci. Eng. A 447, 197-208.

Song, Z., Nakata, K., Wu, A., Liao, J., 2013. Interfacial microstructure and mechanical property of Ti6Al4V/A6061 dissimilar joint by direct laser brazing without filler metal and groove,. Mater. Sci. Eng. A 560, 111-120.

Sun, Z., Ion, J.C., 1995. Laser welding of dissimilar metal combinations. J. Mater. Sci. 30, 4205-4214.

Takemoto, T., Okamoto, I., 1988. On the formation of $\mathrm{TiAl}_{3}$ during reaction between solid Ti and liquid Al. J. Mater. Sci. 23, 1301-1308.

Tomashchuk, I., Sallamand, P., Andrzejewski, H., Grevey, D., 2011. The formation of intermetallics in dissimilar Ti6Al4V/copper/AISI 316 L electron beam and Nd:YAG laser joints. Intermetallics 19, 1466-1473.

Tomashchuk, I., Sallamand, P., Jouvard, J.M., Grevey, D., 2010. The simulation of morphology of dissimilar copper-steel electron beam welds using level set method. Comput. Mater. Sci. 48, 827-836.

Vaidya, W.V., Horstmann, M., Ventzke, V., Pertovski, B., Koçak, M., Kocik, R., Tempus, G., 2010. Improving interfacial properties of a laser beam welded dissimilar joint of aluminum AA6056 and titanium Ti6Al4V for aeronautical applications. J. Mater. Sci. 45, 6242-6254

Zhao, S., Yu, G., He, X., Hu, Y., 2013. Microstructural and mechanical characteristics of laser welding of Ti6Al4V and lead metal. J. Mater. Process. Technol. 212 1520-1527 